\title{
Voltammetric study of the partitioning of macrolide antibiotics at the water/nitrobenzene interface. Relationship to the pharmacokinetic profiling of macrolides
}

\author{
Zoran Mandić \\ Faculty of Chemical Engineering and Technology, University of Zagreb, HR-10000 Zagreb, Croatia \\ Corresponding Author E-mail: zmandic@fkit.hr \\ Tel.: +385-1-4597-164; Fax: +385-1-3733-640
}

Received: July 20, 2014; Revised: August 28, 2014; Published: September 16, 2014

\begin{abstract}
The ion transfer of a series of ionised 14- and 15-membered macrolide compounds across polarised water/nitrobenzene have been studied by cyclic voltammetry. Fourteen-membered macrolides transfer as singly-charged molecules in the wide $\mathrm{pH}$ range, while 15-membered macrolides can transfer as both singly and doubly protonated cations, depending on the $\mathrm{pH}$ of the aqueous solution. The results showed that the formal transfer potentials $\left(\Delta_{o}^{w} \varphi_{i}^{0^{\prime}}\right)$ of the investigated compounds varied to a great extent and that minor changes in macrolide structure caused significant change in the corresponding formal transfer potentials. Among the investigated macrolides, azithromycin had the lowest formal transfer potential and its peculiar ADME behaviour is ascribed to this specific property.
\end{abstract}

Keywords: azithromycin; erythromycin; oleandomycin; clarithromycin; liquid/liquid interface; cyclic voltammetry; pharmacokinetics; lipophilicity; ADME

\section{Introduction}

Macrolides are a class of compounds that exert antibiotic activity against most Gram-positive bacteria and several Gram-negative respiratory and enteric pathogens [1-4]. The main building block common to all macrolides is a large and highly substituted 14-, 15- or 16-membered macrolactone ring on which one to three sugar moieties such as cladinose and desosamine are usually attached. The mechanism of action of macrolides is the inhibition of RNA-directed protein synthesis, usually achieved by binding to the 50S subunit of bacterial ribosomes $[5,6]$.

Erythromycin (1) is a naturally occurring compound first isolated from the Saccharopolyspora erythraea, microorganism found in Philippine soil (Figure 1). It is the prototype 14-membered macrolide compound and almost all other 14- and 15-membered macrolides are semi-synthetic derivatives of erythromycin. The expansion of the erythromycin ring by insertion of nitrogen into the 9a position leads to the 15-membered class of macrolides, widely known as azalides [7]. The most potent and widely prescribed antibiotic belonging to this class is azithromycin (2) (Figure 1). In addition to its broad antibiotic spectrum against Gram-positive bacteria, azithromycin has proven useful in the treatment of some Gram-negative 
respiratory pathogens such as Haemophilus influenza, as well as enterobacteria such as Salmonella [1,2,810].

Macrolide pharmacokinetics differs from other antibiotics. They are able to penetrate a variety of cells and can achieve high intracellular concentrations. This includes increased accumulation in polymorphonuclear cells (PMN) and macrophages, which tend to concentrate at the infection sites, resulting in targeted drug delivery systems [4]. Although all macrolides show similar ADME properties and pharmacokinetics, azithromycin stands out due to its enhanced antimicrobial activity, a more favourable adverse reaction profile and improved pharmacokinetic properties. Azithromycin concentrations are more than 200 times higher intracellularly than extracellularly [4], resulting in the extended exposure of phagocytes and other cells to the drug. It has been found that in the presence of bacteria in the extracellular medium, a rapid release of azithromycin from phagocytes occurs. As an additional advantage, azithromycin retains high and prolonged tissue levels, ensuring that pathogens are continuously exposed to high bactericidal effects [4]. As a result, azithromycin needs significantly shorter administration time and also shows better tolerance to treatment in patients [3].

Such peculiar pharmacokinetics of macrolides, especially the high uptake of azithromycin in PMN and its fast release at the site of infection, is obviously connected with easy and unhindered membrane transport. In several cases, it has been proven that azithromycin transport was governed by $\mathrm{pH}$ differences on both sides of the membranes and that minor changes in the macrolide structure considerably altered their properties, as well as their in vivo availability [4]. The mechanism of macrolide transport is still unclear and the question remains whether the transport of macrolides through biological membranes is governed by active or passive process [4]. Some evidence indicates the simultaneous coexistence of both mechanisms. Both in vivo and in vitro results demonstrate unequal macrolide distribution at different biological membranes; therefore, it seems that the $\mathrm{pH}$-partition hypothesis is not the only factor determining their pharmacokinetic profiles.

Almost all macrolides are weak bases due to the presence of tertiary amine nitrogen at the desosamine sugar (Fig. 1). In addition, azalides possess another amine group as part of macrolactone ring. Due to the $\mathrm{pKa}$ values of these amine groups $\left(\mathrm{pKa}_{1} \sim 8.7\right.$ and $\left.\mathrm{pKa}_{2} \sim 9.3\right)$, macrolides exist as charged species in the physiological and acidic $\mathrm{pH}$ ranges, either as mono-protonated (14-membered macrolides) or doubly protonated (azalides) forms. These properties may indicate that the uptake of macrolides is an electrochemical potential driven process, and that the electrical potential difference through biological membranes may be responsible for governing the overall mechanism of macrolide transport. If this is the case, the uptake of macrolides will depend on actual membrane potential, standard transfer potential at the membrane/water interface and the difference between them.

In order to do in vitro testing and determine whether membrane electrical potential plays an important role in macrolide pharmacology, an appropriate interface model mimicking the in vivo membrane environment must be designed. It has already been proven that liquid/liquid interfaces formed between two immiscible liquids, such as water and an appropriate organic solvent, can be used as a model of biological membrane $[11,12]$. In such cases, a tested compound is dissolved in the system and the interface is electrochemically polarised, resulting in an ionic species transfer across the interface and its redistribution within the two phases. From such measurements, the transfer ability of a compound between two phases is represented by a physico-chemical parameter referred to as standard transfer potential, $\Delta \varphi^{0}$, which can be easily determined using electrochemical measurements. The standard transfer potential of the particular compound is the interfacial potential difference, which will yield equal 
compound activities in both phases [13]. Consequently, the distribution of charged species between two phases will conform to the Nernst-like equation:

$$
\Delta_{o}^{w} \varphi=\Delta_{o}^{w} \varphi_{i}^{0}+\frac{R T}{z F} \ln \left(\frac{a_{i}^{o}}{a_{i}^{w}}\right)=\Delta_{o}^{w} \varphi_{i}^{0^{\prime}}+\frac{R T}{z F} \ln \left(\frac{c_{i}^{o}}{c_{i}^{w}}\right)
$$

where $\Delta_{o}^{w} \varphi$ is potential difference between two phases, $\Delta_{o}^{w} \varphi_{i}^{0}$ and $\Delta_{o}^{w} \varphi_{i}^{0 \prime}$ are standard transfer potential and formal transfer potential, respectively, of the ionised compound $\mathrm{i}$ at the organic solvent/water interface, $a$ and $c$ are activity and concentration of the ionised compound in the corresponding solvent, respectively, and $R, T, z$ and $F$ have their usual thermodynamic meaning.

Solvents having acceptable dielectric constants for dissolving electrolytes suitable for electrochemical measurements and which are usually used for mimicking biological membranes in electrochemistry are nitrobenzene and 1,2-dichloroethane. Both solvents have properties similar to those of biological membranes and relatively high dielectric constants to enable sufficient dissolution of inert electrolytes, and to ensure electric conductivity suitable for performing the electrochemical measurements at their interface with aqueous phase. The interfaces nitrobenzene/water, as well as 1,2-dichloroethane/water are good models for biological membranes, since they enable the rapid and precise determination of the electrochemical properties of ionised biological molecules. Both interfaces have already been used to probe the transfer of ionic drug compounds [14-18].

In the present work, we investigated the electrochemical properties of a series of macrolide compounds at the nitrobenzene/water interface. The structures of the investigated compounds are shown in the Fig.1. The objectives were to measure the standard transfer potentials of macrolide compounds, to determine the mechanisms of their transport at the interface, and to provide some evidence on the importance of in vivo membrane electrical potential on the pharmacokinetics of macrolides. The value of standard transfer potential is correlated with the free energy of transfer of ionized species, $\Delta G=-z F \Delta \varphi$. Lower the absolute value of standard transfer potential of the molecule becomes, higher is its negative free energy, and the molecule crosses the interface easier.

\section{Experimental}

Erythromycin (1), clarithromycin (3) and oleandomycin (9) were purchased from Aldrich.

Azithromycin (2) was obtained from PLIVA d.d. as dihydrate, a 3-decladynosil derivative of azithromycin (4) 9a-aza-9-deoxo-9-dihydro-9a-homoerythromycin A (DHL) (5) and its 3-decladinosyl derivative (6), 3'-Ndemetyl-N-methyl-9a-aza-9-deoxo-9-dihydro-9a-homoerythromycin A (7), 3'-N-demetyl-9a-aza-9-deoxo-9dihydro-9a-homoerythromycin A (8) were synthesised in PLIVA d.d. from azithromycin as a starting compound, according to the procedure described previously [7], and with a purity higher than $95 \%$ as determined by HPLC analysis. 

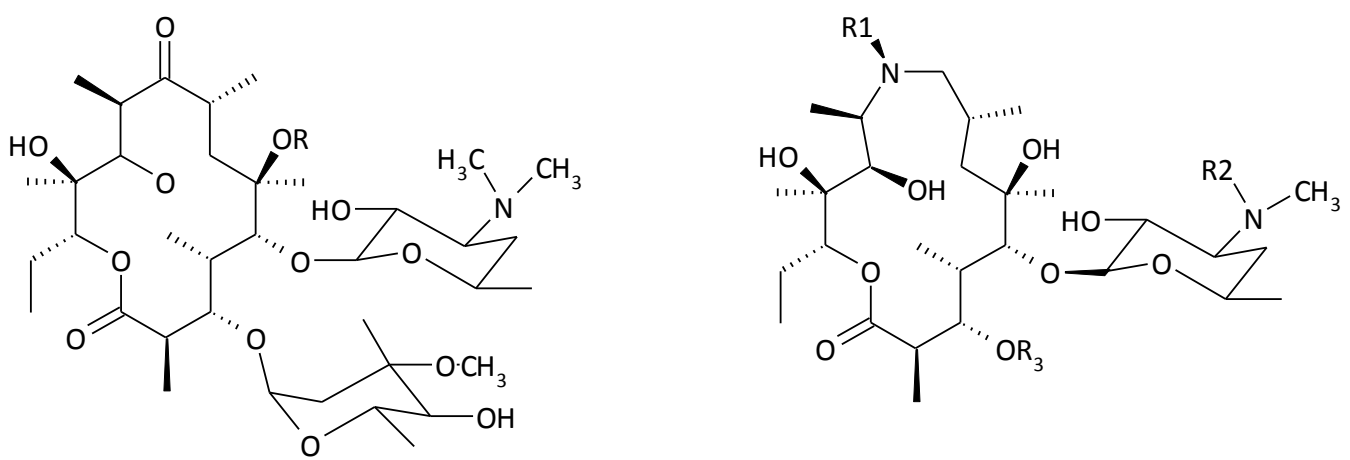

$$
\begin{aligned}
& \text { 1: } \mathrm{R}=\mathrm{H} \\
& \text { 3: } \mathrm{R}=\mathrm{CH}_{3}
\end{aligned}
$$
2: $\mathrm{R} 1=\mathrm{R} 2=\mathrm{CH}_{3} ; \mathrm{R} 3=\mathrm{Cld}$
4: $\mathrm{R} 1=\mathrm{R} 2=\mathrm{CH} 3 ; \mathrm{R} 3=\mathrm{H}$
5: $\mathrm{R} 1=\mathrm{H} ; \mathrm{R} 2=\mathrm{CH} 3 ; \mathrm{R} 3=\mathrm{Cld}$
6: $\mathrm{R} 1=\mathrm{H} ; \mathrm{R} 2=\mathrm{CH} 3 ; \mathrm{R} 3=\mathrm{H}$
7: $\mathrm{R} 1=\mathrm{CH} 3 ; \mathrm{R} 2=\mathrm{H} ; \mathrm{R} 3=\mathrm{Cld}$
8: $\mathrm{R} 1=\mathrm{R} 2=\mathrm{H} ; \mathrm{R} 3=\mathrm{Cld}$

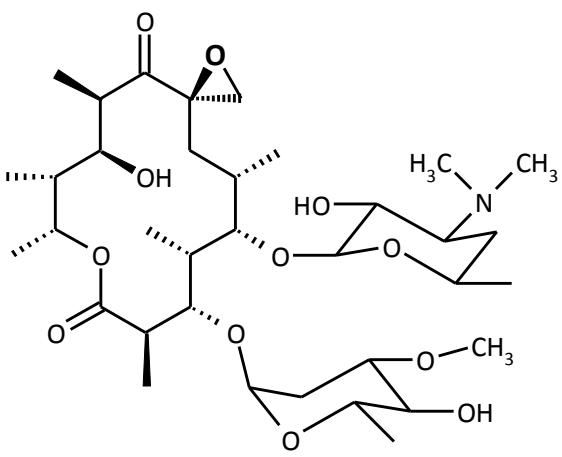

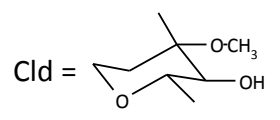

9

Figure 1: The structures of antibiotics investigated in this work: erythromycin (1), azithromycin (2), clarithromycin (3), decladinosil derivative of azithromycin (4), DHL (5), decladinosil derivative of $D H L$ (6), 3'-N-demethylated derivative of azithromycin (7), 3'-N-demethylated derivative of $\mathrm{DHL}(\mathbf{8})$, oleandomycin (9).

The transfer of ionised antibiotics was studied using cyclic voltammetry at the water/nitrobenzene interface and with an interfacial area of $0.12 \mathrm{~cm}^{2}$. The investigated antibiotics were dissolved in a aqueous phase that consisted of a Britton-Robinson buffer of varying $\mathrm{pH}$. The concentration of antibiotics was 2 $\mathrm{mM}$. Tetrabutylammonium tetraphenylborate $\left(\mathrm{Bu}_{4} \mathrm{NPh}_{4} \mathrm{~B}\right)$ was used as a supporting electrolyte in the nitrobenzene phase. The cell can schematically be shown as:

$$
\begin{array}{c|c||c|c}
\mathrm{Ag} / \mathrm{AgCl}(0.1 \mathrm{M} \mathrm{LiCl}) & \begin{array}{c}
0.1 \mathrm{M} \mathrm{BR} \text { buffer, } \\
\text { Varying } \mathrm{pH} \\
\text { (aqueous phase) }
\end{array} & 0.05 \mathrm{M} \mathrm{Bu}_{4} \mathrm{NBPh}_{4} & \begin{array}{c}
0.1 \mathrm{M} \mathrm{Bu}_{4} \mathrm{NCl} \\
\mathrm{AgCl} / \mathrm{Ag}
\end{array} \\
\text { (aqueous phase) } & \begin{array}{c}
\text { (nitrobenzene) } \\
\text { (aqueous phase) }
\end{array}
\end{array}
$$

Four electrode potentiostat (PAR M263A) with positive feedback IR compensation was used for performing electrochemical measurements. A platinum sheet and $\mathrm{Ag} / \mathrm{AgCl}$ electrode served in each phase as counter and reference electrodes, respectively. The silver wire for the nitrobenzene solution was immersed in a $0.1 \mathrm{M}$ aqueous solution of tetrabutylammonium chloride (Bu4NCl).

Formal transfer potentials of the investigated antibiotics were determined by measuring their half-wave potentials, $\Delta_{o}^{w} E_{i, 1 / 2}^{0 r}$. The experimentally obtained values were transposed to the Galvani potential scale by measuring the half-wave potential of tetramethylammonium ion $\left(\mathrm{Me}_{4} \mathrm{~N}^{+}\right)$, for which absolute Galvani potential at water/nitrobenzene is known [19]. All potentials quoted in this paper are potentials of aqueous phase with respect to the nitrobenzene phase. 
Ionization constants, $\mathrm{pKa}$, and $\log P$ values were determined by potentiometric titration method (Sirius analytical, GLpKa). All measurements were carried out at constant temperature of $25{ }^{\circ} \mathrm{C}$, constant ionic strength of $0.15 \mathrm{M} \mathrm{KCl}$ and with continuous flow of argon to prevent the absorption of $\mathrm{CO}_{2}$ from the atmosphere. The $\mathrm{pH}$-electrode was standardized using Sirius Four-PlusTM procedure.

\section{Results and Discussion}

Electrochemical properties of the investigated macrolides and their distribution at water/nitrobenzene interface depend on their $\mathrm{pH}$ dependent speciation. Fourteen-membered macrolides, such as erythromycin (1) and clarithromycin (3) possess a tertiary amine group with a pKa value of $9.3 \pm 0.05$, making this class of macrolides weak bases existing as singly charged forms in a neutral and acidic $\mathrm{pH}$ range. Macrocyclic amine groups of azalides introduce additional nitrogen into 15-membered macrolides with an ionisation constant measured to be around $\mathrm{pKa}=8.7$. Since these ionisation constants present global values and no microionisation data were available in the literature, the exact speciation of the azalide antibiotics, especially in a slightly basic solution, is impossible to discern.

Transfer properties of the investigated macrolides, as well as their formal transfer potentials, were investigated by cyclic voltammetry as a function of aqueous $\mathrm{pH}$. As was expected, the results could be grouped into two categories, depending on the number of basic nitrogen atoms in the molecule.

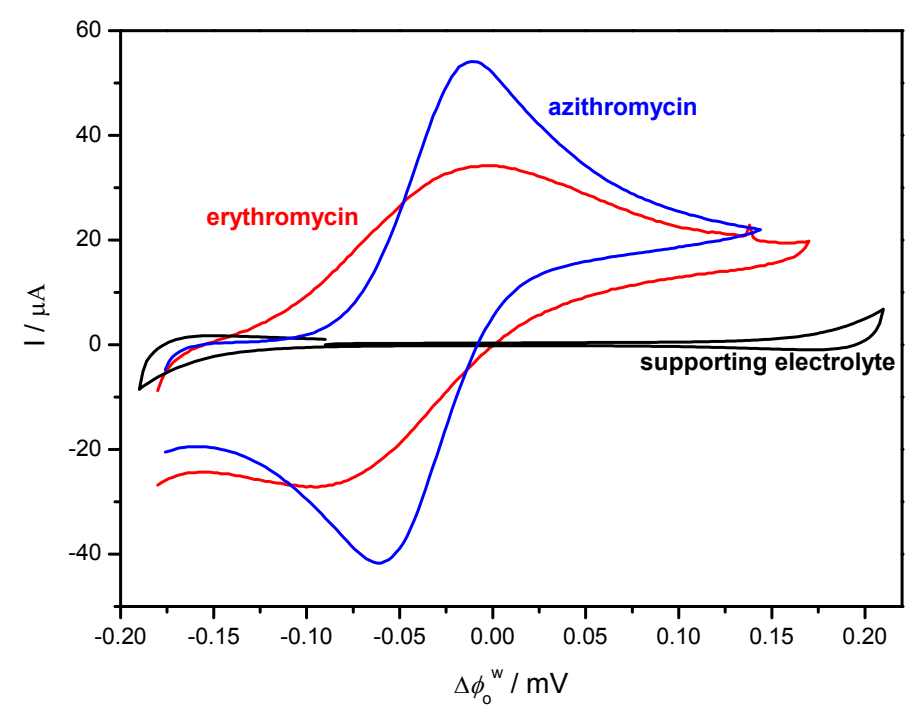

Figure 2: Cyclic voltammograms of erythromycin and azithromycin at a pH of aqueous phase 5.8. Scan rate: $20 \mathrm{mV} / \mathrm{s}$.

The comparison of the cyclic voltammograms of azithromycin and erythromycin taken at aqueous phase $\mathrm{pH}=5.8$, where both compounds exist in fully protonated forms, is shown in Fig. 2. Only one reversible, diffusion-controlled wave was observed for each compound at this $\mathrm{pH}$ value. In an anodic potential direction, a transfer of protonated forms from the aqueous to nitrobenzene phase took place, giving rise to positive currents, while negative currents in the cathodic potential sweep represented the transfer of the same species back from the nitrobenzene to aqueous phase. The linearity of the current peak height with the square root of the scan rate revealed diffusion control of the transfer process. It was found that diffusion coefficients calculated using Randles-Ševčik equation depended on the actual $\mathrm{pH}$ of the aqueous phase. For azithromycin diffusion coefficients in aqueous phase ranged from $1.3 \times 10^{-5} \mathrm{~cm}^{2} \mathrm{~s}^{-1}$ at $\mathrm{pH} 2$ to $6.8 \times 10^{-6} \mathrm{~cm}^{2} \mathrm{~s}^{-1}$ at $\mathrm{pH}$ 8.6. This can be explained by the complex equilibrium of ionized species at the 
interface as already described by Velický et al. [20]. No kinetically slow steps were detected in the cyclic voltammograms. Anodic and cathodic current peak separations being close to 30 and $60 \mathrm{mV}$ for azithromycin and erythromycin, respectively, confirmed doubly-protonated azithromycin and singlyprotonated erythromycin to be the predominant species at acidic $\mathrm{pHs}$ and were involved in the interfacial transfer reactions:

$$
\begin{aligned}
& \mathrm{AzH}_{2}^{2+}(\mathrm{w}) \rightleftarrows \mathrm{AzH}_{2}^{2+}(\mathrm{NB}) \\
& \mathrm{ErH}^{+}(\mathrm{w}) \rightleftarrows \mathrm{ErH}^{+}(\mathrm{NB})
\end{aligned}
$$

The half-wave potentials determined by these measurements were related to the formal transfer potentials of monoprotonated erythromycin molecules and diprotonated azithromycin molecules according to the following equation [21]:

$$
\Delta_{o}^{w} \varphi_{1 / 2}=\Delta_{o}^{w} \varphi_{i}^{0^{\prime}}-\frac{R T}{z F} \ln \sqrt{\frac{D_{i}^{o}}{D_{i}^{w}}}
$$

where $D_{i}^{O}$ and $D_{i}^{W}$ are diffusion coefficients of transferring species in nitrobenzene and aqueous phases, respectively. Using equation (4), the formal transfer potentials of erythromycin and azithromycin were calculated assuming the proportionality of diffusion coefficients with the viscosities of water and nitrobenzene (Walden rule). They amounted to $\Delta_{O}^{w} \varphi_{E r H^{+}}^{0^{\prime}}=-58 \mathrm{mV}$ and $\Delta_{o}^{w} \varphi_{\mathrm{AzH}_{2}^{2^{2+}}}^{0^{\prime}}=-46 \mathrm{mV}$ for erythromycin and azithromycin, respectively.

No changes in the cyclic voltammograms of azithromycin and erythromycin were observed in the $\mathrm{pH}$ range 2-6. Above $\mathrm{pH} \mathrm{6,} \mathrm{cyclic} \mathrm{voltammograms} \mathrm{for} \mathrm{erythromycin} \mathrm{shifted} \mathrm{toward} \mathrm{more} \mathrm{positive} \mathrm{potentials}$ with a slope close to $60 \mathrm{mV} / \mathrm{pH}$, while retaining its shape and reversibility. However, the electrochemical behaviour of azithromycin proved more complex. Between $\mathrm{pH} \mathrm{6-7,} \mathrm{a} \mathrm{second} \mathrm{current} \mathrm{wave} \mathrm{appeared} \mathrm{at}$ more positive potentials, whereas the height of the first wave decreased (Fig. 3a). Above pH 7.5, the first current wave completely disappeared and the second wave shifted toward more positive potentials (Fig. $3 b$ ), with the slope varying from 30 to $60 \mathrm{mV} / \mathrm{pH}$ (Figure 4).
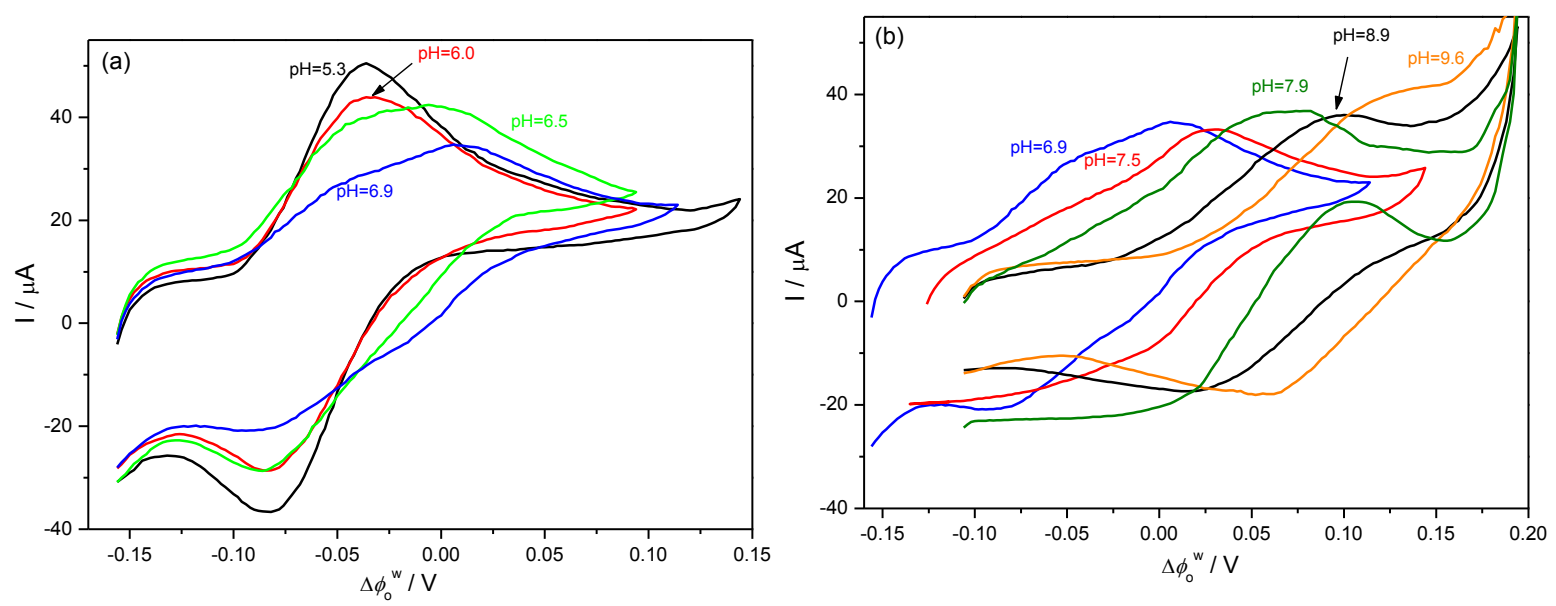

Figure 3. Cyclic voltammograms of azithromycin at various aqueous phase $\mathrm{pH}$. Actual pHs indicated on the graphs. Scan rate $=20 \mathrm{mV} / \mathrm{s}$. 


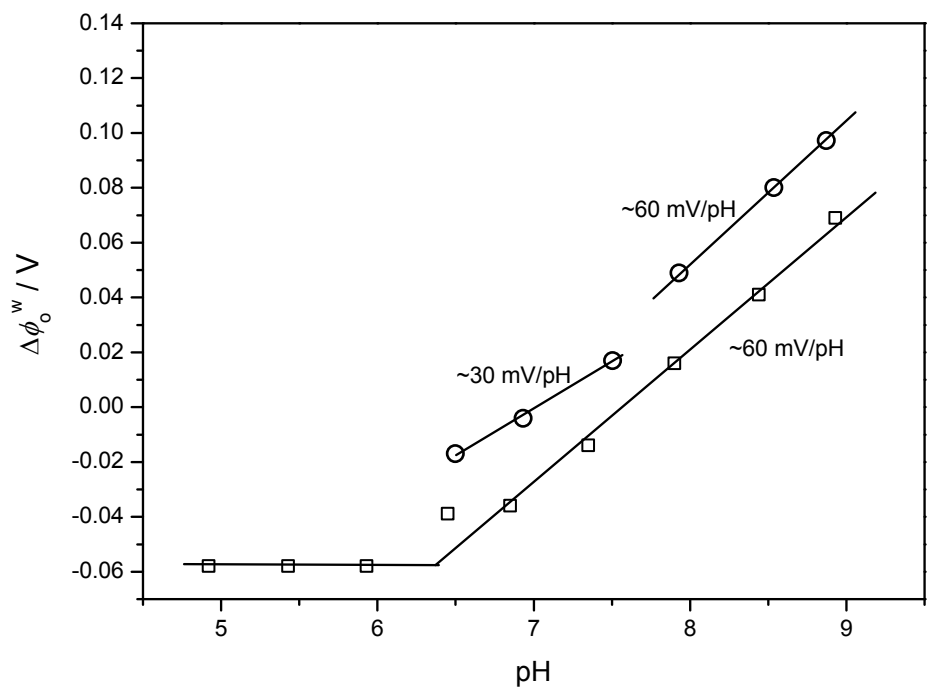

Figure 4: $\mathrm{pH}$ dependence of the transfer potentials of erythromycin (squares) and azithromycin (circles).

These results indicate that in contrast to erythromycin molecules, the mechanism of azithromycin transfer changed when moving from an acidic towards a basic solution. It appears reasonable to assume that when aqueous solution $\mathrm{pH}$ approaches the neutral and slightly basic region, azithromycin will start to deprotonate and as neutral molecules redistribute between the two phases. In such a case, a neutral form of azithromycin will be transferred to nitrobenzene as a potentially independent process and will act as a protonophore, facilitating proton transfer from the aqueous to nitrobenzene phase according to the equation (5):

$$
\mathrm{Az}(\mathrm{NB})+\mathrm{H}^{+}(\mathrm{w}) \rightleftarrows \mathrm{AzH}^{+}(\mathrm{NB})
$$

The anodic and cathodic peak separation in basic solutions is around $60 \mathrm{mV}$ indicating the transfer of singly protonated species. Taking into account two protonation sites of azithromycin, with global pKa values similar to one another $(\Delta \mathrm{p} K a \sim 0.5)$, it is possible for both monoprotonated azithromycin microspecies to transfer simultaneously from aqueous to nitrobenzene phase within the investigated $\mathrm{pH}$ range. Lipophilicities of both protonated micro-forms are expected to be the same, since no evidence could be found in the literature of the potential conformational changes induced by the positive charge on either protonation site of the azithromycin molecule. Consequently, the transfer potentials of these two monoprotonated species should not differ by a considerable amount and could not be discerned in the cyclic voltammetry measurements.

Formal transfer potential of the mono-protonated azithromycin molecule can be estimated using the extrapolation of $\Delta_{o}^{w} \varphi_{1 / 2}$ vs. $\mathrm{pH}$ data selected in the $\mathrm{pH}$ range 8-10 (see Fig. 4) [22]:

$$
\Delta_{o}^{w} \varphi_{1 / 2}=\Delta_{o}^{w} \varphi_{A z H^{+}}^{0^{\prime}}+\frac{2.303 R T}{F}\left(\log P_{A z}^{N B}-p K_{a}^{w}+p H\right)
$$


where $\log P_{A z}^{N B}$ is the partition coefficient between water and nitrobenzene and $p K_{a}^{w}$ is the ionisation constant of mono-protonated azithromycin in water. From the experimental points indicated in Fig. 4 and approximating $\log P_{A z}^{N B}$ to the known partition coefficient of azithromycin in octanol, $\log P_{A z}^{O c t}$, the value of the formal transfer potential of mono-protonated azithromycin was calculated to $\Delta_{O}^{w} \varphi_{A z H^{+}}^{0^{\prime}}=-130 \mathrm{mV}$.

The two macrolides described above, erythromycin and azithromycin, are prototype compounds representing 14- and 15-membered macrolides. All other investigated macrolides showed electrochemical behaviour similar to either one of these two compounds, depending on which class of macrolides they belonged to: 14-membered macrolides with one protonation site or 15-membered macrolides with two protonation sites. Thus, clarithromycin (3) and oleandomycin (9) exhibited one reversible current wave, representing the transfer of their protonated forms and the behaviour of other five azalide compounds, while 4-8 was consistent with the azithromycin transfer exhibiting two different types of transfer mechanism. However, the formal transfer potentials among these compounds vary, indicating that different energies are involved in the transfer processes. The values of formal transfer potentials, $\Delta_{o}^{w} \varphi_{i}^{0^{\prime}}$, for mono-protonated 14-membered macrolides and for both mono- and di-protonated azalides are shown in Table 1.

Table 1: Formal transfer potentials of investigated compounds.

\begin{tabular}{|c|c|c|c|c|}
\hline & \multirow{2}{*}{ Macrolides } & \multirow{2}{*}{$\log P$} & \multicolumn{2}{|c|}{$\Delta_{o}^{w} \varphi_{i}^{0^{\prime}} / \mathbf{m V}$} \\
\hline & & & Monoprotonated & Diprotonated \\
\hline \multirow{6}{*}{$\begin{array}{c}15- \\
\text { membered }\end{array}$} & azithromycin, $\mathbf{2}$ & 3.98 & $-130^{*}$ & -46 \\
\hline & $\mathrm{DHL}, 5$ & 3.63 & $-90^{*}$ & -4 \\
\hline & $\begin{array}{l}3 \text { '-N-demethyl } \\
\text { azithromycin, } 7\end{array}$ & 3.62 & $-90^{*}$ & -5 \\
\hline & 3'-N-demethyl DHL, 8 & 3.45 & $-60^{*}$ & +24 \\
\hline & $\begin{array}{l}\text { 3-decladinosil } \\
\text { azithromycin, } 4\end{array}$ & 3.11 & $-65^{*}$ & +18 \\
\hline & 3-decladinosil DHL, 6 & 3.03 & $-35^{*}$ & +45 \\
\hline \multirow{3}{*}{$\begin{array}{c}14- \\
\text { membered }\end{array}$} & erythromycin, 1 & 3.02 & -58 & - \\
\hline & claritromycin, 3 & 3.24 & $<-100$ & - \\
\hline & oleandomycin, 9 & 2.76 & -48 & - \\
\hline
\end{tabular}

*Calculated by equation (6) with the assumption of equal water/nitrobenzene and water/octanol partition coefficients and with $p K a=9$ as the average value of two ionisation constants.

Macrolides' ability to pass through biological membranes and to accumulate in high concentrations intracellularly are of paramount importance for their pharmacokinetics, as proven by the significant amount of in vivo and in vitro data accumulated on the subject over the years [4]. In order to reach the site of the infection, macrolides have to cross biological membranes several times. Upon administration, macrolides dissolve in the stomach due to the environment's favourable $\mathrm{pH}$ value $(\mathrm{pH}=1-2)$ for the dissolution of weak bases. After passage of macrolides into the duodenum and further to the jejunum, where $\mathrm{pH}$ microclimates range from 5-7 [23], macrolides still predominantly remain in their charged state. From there, they are able to enter the bloodstream by passive diffusion, either transcellularly through the bilayer surface of epithelial cells or paracellularly. Both neutral and charged forms can participate in 
passive diffusion. Neutral forms can distribute according to the $\mathrm{pH}$-partition hypothesis, while charged molecules can distribute according to the difference between the actual membrane potential and their formal transfer potential $\Delta_{o}^{w} \varphi_{i}^{0^{\prime}}$, as predicted by equation (1).

It is assumed that weak bases such as macrolides are concentrated in the more acidic parts of membranes. This behaviour has already been experimentally observed several times in vivo [4] and was found to be the key process determining macrolide pharmacokinetics. However, it remains puzzling as to why azithromycin, compared to other macrolides, can achieve and retain very high (up to 200 times) intracellular concentrations, especially within polymorphonuclear cells such as neutrophils. Being highly motile, neutrophils are quickly attracted to the site of an infection, where azithromycin is rapidly released. The whole system represents a very efficient drug delivery system. Consequently, azithromycin is administered in patients in single daily doses during no more than two to three days. This is highly advantageous compared to treatment with other macrolides such as erythromycin and clarithromycin, which might achieve similar remedial effects only after a week or 10 days when administered in double or triple daily doses.

High azithromycin accumulation might be partially the result of the involvement of active transmembrane transport, but it nonetheless seems plausible to assume that transmembrane electrical potential is the key factor in macrolide pharmacokinetics. Indeed, when the data given in Table 1 are analysed, it turns out that azithromycin has the lowest formal transfer potential among the investigated macrolide compounds. $\Delta_{o}^{w} \varphi_{i}^{0^{\prime}}$ of a singly-charged molecule of azithromycin, $\mathrm{Az} \mathrm{H}^{+}$, is $-130 \mathrm{mV}$ and even 72 and $82 \mathrm{mV}$ lower than 14-membered mono-protonated erythromycin and oleandomycin, respectively. The lowest $\Delta_{o}^{w} \varphi_{i}^{0^{\prime}}$ means that charged azithromycin has the lowest free energy of transfer to and through the membrane. Although the situation at the biological membrane is more complex due to the involvement of the two membrane interfaces with two membrane/water potential differences, the concept of the distribution of the charged molecules on both sides of the membrane remains valid and follows the equilibrium given by equation 1. Depending on the difference between standard (or formal) transfer potential and the actual membrane potential, the distribution of different molecules at both sides of the membrane might vary to a significant extent.

It is worth noting here that the treatment of neuthrophiles with ionophores such as gramicidin resulted in the reduction of azithromycin uptake in neutrophils [24]. Ionophores increase the permeability of biological membranes to the ionic species dissipating their concentration gradients and consequently reducing the transmembrane electrical gradient. Although decreased uptake of azithromycin in gramicidin treated neutrophils might be the result of the levelling off $\mathrm{pH}$ gradient across the membrane, it might point out also to the importance of the membrane potential on the pharmacokinetics of azithromycin [24].

A comparison of azithromycin to other investigated azalides highlights the importance of tertiary amine groups in the transfer process. The results were consistent with earlier observations that minor changes in the macrolide structure significantly affected their chemical and biological properties.

The favourable influence of the two methyl groups and cladinose sugar moiety on the lipophilic and pharmacokinetic behaviour of azithromycin was demonstrated by the increase of the formal transfer potentials after their elimination from the macrolide scaffold. Each methyl group on the amine contributed about $3.9 \mathrm{~kJ} \mathrm{~mol}^{-1}$ and cladinose sugar even with $6.3 \mathrm{~kJ} \mathrm{~mol}^{-1}$ in lowering free energy of transfer of azithromycin. This could not be explained by their more lipophilic contribution to the overall lipophilicity of 
the azithromycin, at least, not in a significant extent. It is more likely that outstanding membrane transfer properties of azithromycin are connected to its ability to form two conformations, referred to as folded-in and folded-out conformations $[25,26]$. The fraction of each conformation depends on the polarity of its environment and it is possible that azithromycin undergoes conformational change after having been transferred from one phase into another.

\section{Conclusions}

Cyclic voltammetry at the water/nitrobenzene interface has been demonstrated as an important technique for evaluating the influence of the relevant physico-chemical property, $\Delta_{o}^{w} \varphi_{i}^{0^{\prime}}$, as it concerns the pharmacokinetics of macrolides. All macrolides studied in this paper transferred from the aqueous to the nitrobenzene phase at a sufficiently high interfacial potential. Half-wave potential of the 14-membered macrolides shifted toward more positive potentials by $60 \mathrm{mV} / \mathrm{pH}$, while 15 -membered azalide compounds exhibited more complex behaviour. Above $\mathrm{pH} 7$, two mono-protonated species were involved in the transfer.

Azithromycin exhibited the lowest standard transfer potential among all macrolides, which is consistent with its outstanding in vivo behaviour and exceptional pharmacokinetics.

These results show that cyclic voltammetry can be used in pharmaceutical research and development as a fast and simple method for screening out macrolide compounds with potentially good ADME properties.

Acknowledgements: Almost all work and results presented in this paper were done during my work in PLIVA d.d. I am very grateful to Vesna Gabelica Marković, Suzana Žalac and Ognjen Čulić for their wholehearted support. I am also grateful to other colleagues and staff of PLIVA who helped in this work.

\section{References}

[1] G.M. Bright, A.A. Nagel, J. Bordner, J. Antibiot. 41 (1988) 1029-1047.

[2] J. Retsema, A. Girard, W. Schelkly, M. Manousos, M. Anderson, G. Bright, R. Borovoy, L. Brennan, R. Mason, Antimicrob. Agents Chemother. 31 (1987) 1939-1947.

[3] S. Alvarez-Elcoro, M.J. Enzler, Mayo Clinic Proceed., 74 (1999) 613-534.

[4] W. Schönfeld, H.A. Kirst (Eds.), Macrolide Antibiotics, Birkhäser Verlag, Basel-Boston Berlin, 2002.

[5] H.A. Kirst, G.D. Sides, Antimicrob. Agents Chemother. 33 (1989) 1413-1418.

[6] R.C. Goldman, S.W. Fesik, C.C. Doran, Antimicrob Agents Chemother. 34 (1990) 426-431.

[7] S. Djokić, G. Kobrehel, G. Lazarevski, N. Lopotar, Z. Tamburašev, J. Chem. Soc. Perkin Trans. I, (1986) 1881-1890.

[8] R.M. Rakita, K. Jacquespalaz, B.E. Murray, Antimicrob. Agents Chemother. 38 (1994) 1915-1921.

[9] D. Gur, Y. Kayaokay, G. Hascelik, H.E. Akalin, J. Chemother. Suppl. 5 (1993) 151-152.

[10] M.E. Gordillo, K.V. Singh, B.E. Murray, Antimicrob. Agents Chemother. 37 (1993) 1203-1205.

[11] L.E. Morrison, G. Weber, J. Biophys. 52 (1987) 367-379.

[12] A.G. Volkov, D.W. Deamer, Liquid-Liquid Interfaces, Theory and Methods, CRC Press, 1996.

[13] P. Vanysek, Electrochim. Acta 40 (1995) 2841-2847.

[14] M. Velický, A. N.J. Rodgers, R. A.W. Dryfe and K. Tam, ADMET \& DMPK, 2 (2014) 143-156.

[15] G. Bouchard, A. Pagliara, G. P. Van Balen, P. A. Carrupt, B. Testa, V. Gobry, H. H. Girault, G. Caron, G. Ermondi, and R. Fruttero, Helv. Chim. Acta 84 (2001) 375-387. 
[16] S. M. Ulmeanu, H. Jensen, G. Bouchard, P.A. Carrupt, H. Girault, Pharm. Res., 20 (2003) 1317-1322.

[17] R. Gulaboski, F. Borges, C.M. Pereira, M.N.D.S. Cordeiro, J. Garrido, A.F. Silva, Comb. Chem. High Throughput Screen., 10 (2007) 514-526.

[18] L.M. Yudi, A.M. Baruzzi, V. Solis, J. Electroanal. Chem., 360 (1993) 211-219.

[19] T. Wandlowski, V. Mareček, Z. Samec, Electrochim. Acta, 35 (1990) 1173-1175.

[20] M. Velický, K.Y. Tam, R.A.W. Dryfe, J. Electroanal. Chem. 683 (2012) 94-102.

[21] H.H. Girault, D.J. Schiffrin, Electroanal. Chem., 15 (1989) 1-141.

[22] S.M. Ulemanu, H. Jensen, G. Bouchard, P.A. Carrupt, H.H. Girault, Pharm. Res., 20 (2003) 1317-1322.

[23] A. Avdeef, Absorption and Drug Development: Solubility, Permeability, and Charge State, $2^{\text {nd }}$ Ed. John Wiley \& Sons, Inc., 2012.

[24] Unpublished results.

[25] J. R. Everett, J. W. Tyler, J. Chem. Soc. Perkin Trans. 2, (1987) 1659.

[26] P. Novak, Z. Banić Tomišić, P. Tepeš, G. Lazarevski, J. Plavec, G. Turkalj, Org. Biomol. Chem. 3 (2005) 39-47. 